\title{
Efeito da Granulometria do Bagaço de Cana sobre as Características Digestivas e a Contribuição Nutritiva dos Cecotrofos
}

\author{
Flávia da Silva Vieira ${ }^{1}$, Augusto Vidal da Costa Gomes², Marcus Ferreira Pessoa ${ }^{3}$
}

\begin{abstract}
RESUMO - Foram realizados dois experimentos com coelhos mestiços Nova Zelândia Branco x Califórnia, com o objetivo de avaliar o efeito da granulometria da fonte de fibra sobre as características digestivas de coelhos em crescimento e sobre a produção, composição química e a contribuição nutritiva dos cecotrofos, em termos de matéria seca (MS) e proteína bruta (PB). Quatro dietas foram elaboradas com diferentes granulometrias do bagaço de cana com diâmetro geométrico médio (DGM) de 0,231, 0,506, 0,616 e 0,833 mm. O desempenho e os pesos do sistema digestivo cheio, sistema digestivo vazio, conteúdo do sistema digestivo, ceco cheio, ceco vazio e conteúdo cecal não foram afetados significativamente, entretanto o nitrogênio amoniacal do conteúdo cecal aumentou significativamente com o aumento da granulometria do bagaço de cana. Na avaliação da cecotrofia, foi observado efeito linear significativo da granulometria sobre a produção de cecotrofos e o teor de MS e PB ingerido por cecotrofia, porém sua composição química não foi afetada.
\end{abstract}

Palavras-chave: coelho, características digestivas, cecotrofia, tamanho de partícula

\section{Effect Particle Size of Sugar Cane Bagasse on the Digestive Traits and the Cecotrophes Nutritive Contribution}

\begin{abstract}
Two experiments using New Zealand White x Californian rabbits were carried out with the objective of evaluating the effect of fiber source particle size on digestive traits of growing rabbit and the production, chemical composition and cecotrophes nutritive contribuition on dry matter (DM) and crude protein (CP) base. Four diets were prepared with different particle size of sugar cane bagasse with average geometric diameters of $.231, .506, .616$ and $.833 \mathrm{~mm}$. The productive performance and weight of the full and empty digestive tract, digestive tract content, full and empty cecum and cecum content were not affected, however the ammonia nitrogen percentage in the caecum content was significantly increased by increasing particle size of sugar cane bagasse. In cecotrophy evaluation, effects of particle size on cecotrophes production, DM and CP content ingested were observed, but the cecotrophes chemical composition was not affected by diets.
\end{abstract}

Key Words: cecotrophy, digestive traits, particle size, rabbit

\section{Introdução}

O estudo do peso do sistema digestivo de coelhos e do seu conteúdo é importante sob o ponto de vista econômico nas explorações cunículas, porque, quando ocorre sobrecarga no sistema digestivo, especialmente no ceco, geralmente, como conseqüência de baixa velocidade de trânsito, favorece o aparecimento de diarréias, que é a principal causa de mortalidade durante a fase de engorda (Laplace, 1978).

Poucos trabalhos têm evidenciado a relação da granulometria dos ingredientes da dieta com o peso e o volume do sistema digestivo.

Alicatta et al. (1988) utilizaram duas dietas, trabalhando com dois graus de moagem (1,5 e 6,0 mm), e observaram que o volume cecal foi significativa- mente maior $(22 \%)$ na dieta finamente moída. Estudando quatro diferentes granulometrias $(0,461$; 0,635; 0,969 e 1,273) do feno de coastcross como fonte de fibra para coelhos, Rocha et al. (2000) observaram redução linear nos pesos do sistema digestivo vazio, do ceco vazio, do intestino delgado e grosso e do tecido estomacal, com o aumento da granulometria do feno, o que evidencia que as partículas mais finas podem ficar mais tempo retidas no ceco (Laplace \& Lebas, 1977).

A amônia $\left(\mathrm{NH}_{3}\right)$ é o principal produto do catabolismo do nitrogênio no ceco, bem como a principal fonte para a síntese de proteína bacteriana que o coelho pode consumir nos cecotrofos. Os níveis de $\mathrm{NH}_{3}$ cecal descritos na literatura apresentam grande variação, 6,6 a 30 mg\% (Gidenne, 1986), 7,5 a 10 mg\%

\footnotetext{
1 Zootecnista, M.S.

2 Professor do departamento de Nutrição Animal e Pastagens da UFRRJ. E.mail: vidal@ufrrj.br

3 Engenheiro Químico, Aluno de pós-graduação em Nutrição Animal da UFRRJ.
} 
(Fraga, 1998) e 8,79 a 14,26 mg\% (Santiago, 2001), o que demonstra que a concentração de $\mathrm{NH}_{3}$ pode variar com o tipo da dieta. Carabaño (1985) não encontrou influência do nível de fibra da dieta sobre a concentração de $\mathrm{NH}_{3}$ no ceco, embora assinale que, ao aumentar o nível de proteína de concentrados, eleva-se a concentração de $\mathrm{NH}_{3}$, especialmente quando o nível de fibra era elevado. Posteriormente, Carabaño et al. (1989) estudaram a substituição da alfafa pelo farelo de girassol e palha de cevada, as dietas apresentavam 36,4 e $46,6 \%$ de FDN, respectivamente. Os autores mostraram que a dieta alta em fibra proporcionou aumento significativo de aproximadamente $37,4 \%$ de $\mathrm{NH}_{3}$ no ceco. Isso pode ter ocorrido pela alta degradabilidade de proteína oriunda da dieta à base de farelo de girassol, associada ao seu menor teor de fibra.

Para que a população cecal se mantenha em equilíbrio é necessário que o conteúdo do ceco apresente $\mathrm{pH}$ ácido, sendo que os valores obtidos por diversos autores estão entre 5,7 e 6,3, embora alguns tenham encontrado valores próximos à neutralidade, entre 6,7 e 7,2 (Gomes, 1996).

A cecotrofia, conforme Proto (1984), consiste num mecanismo de adaptação às difíceis condições ambientais, particularmente alimentares, pelo qual, como resultado da digestão dos alimentos pelos coelhos, dois tipos de excreta são produzidos: um eliminado na forma de fezes duras e outro na forma de fezes moles, denominadas cecotrofos, os quais diferem entre si tanto pelo processo de formação e excreção quanto pela composição química. Além de fornecer determinada quantidade de nutrientes para os animais, o cecotrofo permite a reciclagem de parte do alimento não digerido, o que possibilita sua melhor utilização.

Trabalhos têm mostrado que a excreção de cecotrofos e a contribução nutritiva podem variar com a natureza da dieta. Carabaño et al. (1988) citam valores de excreção que variam de 14,98 a 29,50 g de matéria seca por dia. Quanto à contribuição de proteína bruta e de matéria seca pelos cecotrofos, Gomes \& Ferreira (1999) citam valores de 21,35 a $28,55 \%$ e de 15,34 a $18,48 \%$, respectivamente.

O objetivo do presente trabalho foi avaliar o efeito de quatro tamanhos de partículas do bagaço de cana sobre as características digestivas e produção, composição química e contribuição dos cecotrofos em termos de matéria seca e proteína bruta para coelhos em crescimento.

\section{Material e Métodos}

Foram realizados dois experimentos com coelhos Nova Zelândia Branco x Califórnia, de ambos os sexos. O primeiro foi realizado no Setor de Cunicultura do Instituto de Zootecnia da Universidade Federal Rural do Rio de Janeiro (UFRRJ), com o objetivo de estudar o efeito de diferentes granulometrias sobre as características digestivas de coelhos em crescimento. Foram utilizados 40 animais desmamados aos 39 dias com peso médio de $944 \pm 10 \mathrm{~g}$, alojados ao acaso em gaiolas experimentais individuais equipadas com comedouro e bebedouro e distribuídos em um delineamento inteiramente ao acaso com quatro tratamentos e dez repetições. Os animais foram abatidos às $14 \mathrm{~h}$ com peso médio de $2370 \pm 50$ g. Após o abate, retirou-se o sistema digestivo intacto, excluindo-se órgãos anexos como fígado e pâncreas, e obtiveramse o peso do sistema digestivo cheio, peso do ceco cheio, peso do tecido cecal, peso do conteúdo cecal e o peso do sistema digestivo vazio. O conteúdo cecal foi homogeneizado e o $\mathrm{pH}$, imediatamente medido utilizando-se um potenciômetro. Após a medição do $\mathrm{pH}$, o conteúdo cecal foi acondicionado e congelado a $-10^{\circ} \mathrm{C}$ para análises posteriores.

O segundo experimento foi realizado nas dependências do Departamento de Nutrição Animal e Pastagens do Instituto de Zootecnia da Universidade Federal Rural do Rio de Janeiro (UFRRJ), visando estudar o efeito das diferentes granulometrias sobre a produção total de cecotrofos, sua composição química e contribuição nutritiva em matéria seca e proteína bruta. Foram utilizados 32 animais (oito animais por tratamento), com peso médio de $2940 \pm 70$ g. Os animais foram alojados em gaiolas individuais de metabolismo equipadas com bebedouro e comedouro e com uma tela de náilon em toda a extensão do fundo da gaiola, para o recolhimento dos cecotrofos. Os animais tiveram um período de adaptação às dietas de dez dias, durante os quais se controlou o consumo de ração.

Com o objetivo de evitar a cecotrofia, cada animal recebeu um colar circular de madeira medindo $25 \mathrm{~cm}$ de diâmetro com um orifício central de $7 \mathrm{~cm}$. O colar foi colocado às $14 \mathrm{~h}$ e retirado ao completar 24 horas. Durante esse período, controlou-se o consumo de ração e colheram-se os cecotrofos de $2 \mathrm{em} 2$ horas. Os cecotrofos foram acondicionados e congelados a $-10^{\circ} \mathrm{C}$ para posteriores análises químicas.

As dietas foram formuladas utilizando-se o bagaço

R. Bras. Zootec., v.32, n.4, p.935-941, 2003 
Tabela 1 - Composição percentual da dieta experimental Table 1 - Percentual composition of the experimental diet

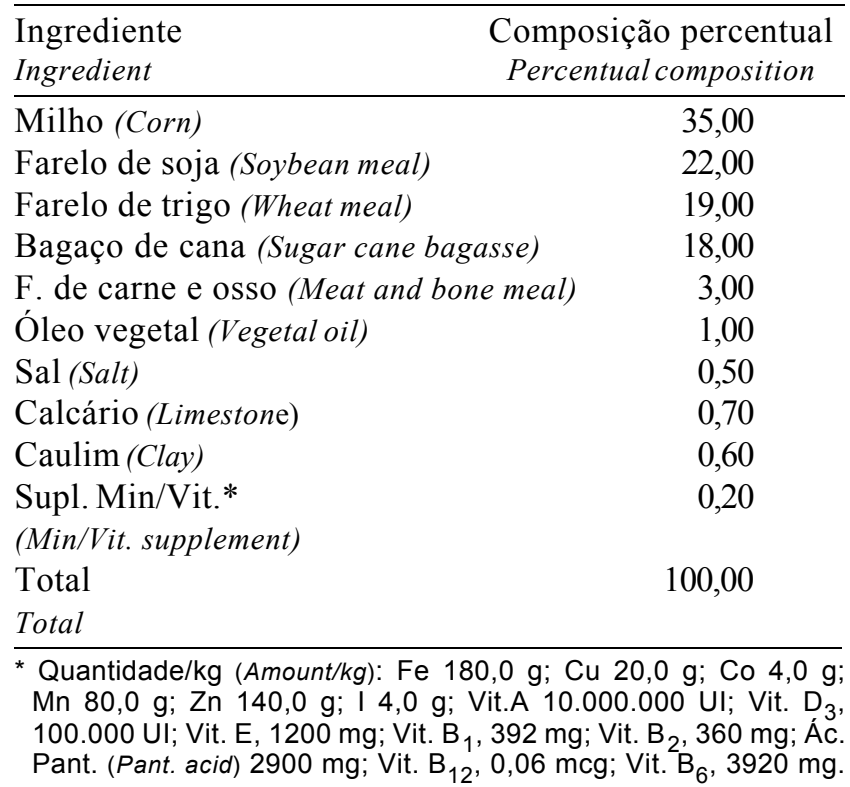

de cana como principal fonte de fibra e caracterizavam-se pelas diferentes granulometrias do bagaço, para tal empregou-se um moinho de martelos, e peneiras com furos de $1,0,3,0,5,0$ e 7,0mm de diâmetro. Segundo Martin (1988), o grau de moagem é influenciado por vários fatores envolvidos no processo, razão pela qual cada granulometria foi caracterizada pelos valores de diâmetro geométrico médio das partículas (DGM) segundo Zanotto \& Bellaver (1996). Os valores obtidos para o DGM foram: 0,231, $0,506,0,616$ e $0,833 \mathrm{~mm}$, originando as quatro dietas experimentais cuja fórmula e composição química encontram-se nas Tabelas 1 e 2, respectivamente. A dieta experimental foi formulada para atender às exigências de coelhos em crescimento, de acordo com as recomendações de Lebas et al. (1986). Essas dietas foram peletizadas, obtendo-se pélete com $4,5 \mathrm{~mm}$ de diâmetro e 8,0 mm de comprimento.

Tabela 2 - Composição química das dietas expressa em percentagem na base seca Table 2 - Chemical composition of diets on dry matter

\begin{tabular}{|c|c|c|c|c|}
\hline \multirow[b]{2}{*}{$\begin{array}{l}\text { Nutriente (\%) } \\
\text { Nutrient }\end{array}$} & \multicolumn{4}{|c|}{$\begin{array}{c}\text { Diâmetro geométrico médio }(\mathrm{mm}) \\
\text { Average geometric diameters }\end{array}$} \\
\hline & 0,231 & 0,506 & 0,616 & 0,833 \\
\hline $\begin{array}{l}\text { Matéria seca } \\
\text { Dry matter }\end{array}$ & 86,40 & 87,09 & 87,66 & 87,58 \\
\hline $\begin{array}{l}\text { Proteína bruta } \\
\text { Crude protein }\end{array}$ & 19,60 & 19,30 & 19,50 & 19,39 \\
\hline $\begin{array}{l}\text { Matéria mineral } \\
\text { Ash }\end{array}$ & 6,81 & 6,74 & 6,46 & 6,49 \\
\hline $\begin{array}{l}\text { Fibra em detergente neutro } \\
\text { Neutral detergent fiber }\end{array}$ & 31,93 & 31,55 & 31,69 & 31,92 \\
\hline $\begin{array}{l}\text { Fibra em detergente ácido } \\
\text { Acid detergent fiber }\end{array}$ & 15,20 & 16,12 & 15,46 & 15,34 \\
\hline $\begin{array}{l}\text { Matéria orgânica } \\
\text { Organic matter }\end{array}$ & 93,19 & 93,26 & 93,54 & 91,51 \\
\hline $\begin{array}{l}\text { Energia bruta }{ }^{1} \\
\text { Gross energy }\end{array}$ & 4582,01 & 4567,09 & 4555,01 & 4505,56 \\
\hline $\begin{array}{l}\text { Cálcio } \\
\text { Calcium }\end{array}$ & 0,97 & 0,96 & 0,88 & 0,97 \\
\hline $\begin{array}{l}\text { Fósforo } \\
\text { Phosphorus }\end{array}$ & 0,76 & 0,77 & 0,75 & 0,78 \\
\hline
\end{tabular}

${ }^{1}$ Energia bruta (kcal/kg) (Gross energy).

As dietas e os cecotrofos foram submetidos a análises de matéria seca (MS), proteína bruta (PB) e matéria mineral (MM), de acordo com os métodos da AOAC (1984), assim como a determinação da amônia do conteúdo cecal. A energia bruta foi determinada usando-se a bomba calorimétrica PARR, de acordo com Harris (1970). Fibra em detergente ácido
(FDA) e fibra em detergente neutro (FDN) foram determinadas seguindo a metodologia descrita por Van Soest (1967) e Van Soest et al. (1991).

A análise estatística foi realizada segundo o programa SAEG - Sistema de análises estatísticas e genéticas (UFV, 1997) empregando-se os modelos de análises de variância e regressão. 


\section{Resultados e Discussão}

O consumo diário de ração, ganho de peso diário e conversão alimentar, não foram afetados $(\mathrm{P}>0,05)$ pelo tamanho da partícula do bagaço de cana. O ganho médio diário obtido de 40,73 g está próximo ao citado por Ferreira (1991), que, ao trabalhar com bagaço de cana in natura, cita ganho de peso diário de $41,3 \mathrm{~g}$, porém é superior ao observado por Valente et al. (2000) que ao trabalharem com suplementação enzimática em dietas para coelhos relataram, em média, 31,8 g de ganho diário. A média obtida para conversão alimentar foi de 2,82, sendo superior à citada por Valente et al. (2000), porém está próxima aos valores obtidos por Gomes (1996), que oscilaram de 2,31 a 2,93.

A concentração de $\mathrm{NH}_{3}$ e o $\mathrm{pH}$ do conteúdo cecal encontram-se na Tabela 3.

\begin{tabular}{|c|c|c|c|c|c|}
\hline Table 3 - & $\begin{array}{l}\text { Amoniun wh } \\
\text { content }\end{array}$ & ole con & entratio & and $p H$ & of cecal \\
\hline \multirow[b]{2}{*}{$\begin{array}{l}\text { Variável } \\
\text { Variable }\end{array}$} & \multicolumn{4}{|c|}{$\begin{array}{c}\text { Diâmetro geométrico médio }(\mathrm{mm}) \\
\text { Average geometric diameter }\end{array}$} & \multirow{2}{*}{$\begin{array}{l}\text { CV } \\
(\%)\end{array}$} \\
\hline & 0,231 & 0,506 & 0,616 & 0,833 & \\
\hline \multirow{2}{*}{$\begin{array}{l}\mathrm{NH} 3(\mathrm{mg} \%)^{1} \\
\mathrm{pH}\end{array}$} & 18,64 & 21,00 & 24,30 & 24,06 & 18,07 \\
\hline & 6,64 & 6,75 & 6,84 & 6,73 & 3,53 \\
\hline
\end{tabular}

Foi observado aumento linear $(\mathrm{P}<0,05)$ da concentração de $\mathrm{NH}_{3}$ no ceco, com o aumento da granulometria do bagaço de cana. Observa-se na Figura 1 que cada $0,1 \mathrm{~mm}$ de aumento no DGM das partículas correspondeu a incremento de $1 \mathrm{mg} \%$ de $\mathrm{NH}_{3}$ no ceco. Tal comportamento pode ser atribuído à maior velocidade de trânsito da digesta com o aumento do tamanho de partícula, fazendo com que maiores quantidades de proteína não digerida chegassem ao ceco e, conseqüentemente, maior produção de $\mathrm{NH}_{3}$ cecal. Em termos percentuais, foi observado aumento de 30,36\% na concentração de amônia, sendo o maior valor observado para DGM 0,616 mm.

Trabalhando com dietas para coelhos suplementadas ou não com complexo enzimático, Dias (1999) e Santiago et al. (2001) encontraram valores médios de 5,56 e $10,64 \mathrm{mg} \%$ de $\mathrm{NH}_{3}$, os quais são inferiores ao observado neste experimento, em média de $22 \mathrm{mg} \%$.

Não foi observado efeito significativo $(\mathrm{P}>0,05)$ para os pesos de sistema digestivo cheio, sistema digestivo vazio, conteúdo do sistema digestivo, ceco cheio, ceco vazio e conteúdo cecal com o aumento do tamanho de partícula do bagaço de cana.

Alicatta et al. (1988), trabalhando com duas granulometrias (uma fina, $1,5 \mathrm{~mm}$, e outra grossa, $6,0 \mathrm{~mm}$ ), observaram que o volume cecal foi significativamente maior (22\%) na dieta com a granulometria fina, o que não ocorreu neste trabalho.

Tabela 4 - Peso vivo e do sistema digestivo com base na matéria natural Table 4 - Live weigth and digestive system weight in natural matter

\begin{tabular}{|c|c|c|c|c|c|}
\hline \multirow[b]{2}{*}{$\begin{array}{l}\text { Variável }(\mathrm{g}) \\
\text { Variable }\end{array}$} & \multicolumn{4}{|c|}{$\begin{array}{c}\text { Diâmetro geométrico médio }(\mathrm{mm}) \\
\text { Average geometric diameter }\end{array}$} & \multirow[t]{2}{*}{ CV (\%) } \\
\hline & 0,231 & 0,506 & 0,616 & 0,833 & \\
\hline $\begin{array}{l}\text { Peso vivo } \\
\text { Live weight }\end{array}$ & $2.347,50$ & $2.395,63$ & $2.330,00$ & $2.418,50$ & 8,08 \\
\hline $\begin{array}{l}\text { Sistema digestivo cheio } \\
\text { Full digestive system }\end{array}$ & 433,31 & 428,88 & 408,33 & 397,01 & 11,63 \\
\hline $\begin{array}{l}\text { Sistema digestivo vazio } \\
\text { Empty digestive system }\end{array}$ & 152,62 & 151,85 & 150,54 & 149,56 & 10,37 \\
\hline $\begin{array}{l}\text { Conteúdo do sistema digestivo } \\
\text { Digestve system content }\end{array}$ & 280,69 & 277,03 & 257,80 & 247,45 & 15,82 \\
\hline $\begin{array}{l}\text { Ceco cheio } \\
\text { Full caecal }\end{array}$ & 155,43 & 131,31 & 128,59 & 137,08 & 22,45 \\
\hline $\begin{array}{l}\text { Ceco vazio } \\
\text { Empty caecal }\end{array}$ & 39,96 & 38,71 & 38,97 & 39,81 & 12,43 \\
\hline $\begin{array}{l}\text { Conteúdo cecal } \\
\text { Content caecal }\end{array}$ & 115,47 & 92,60 & 89,63 & 97,28 & 28,26 \\
\hline
\end{tabular}




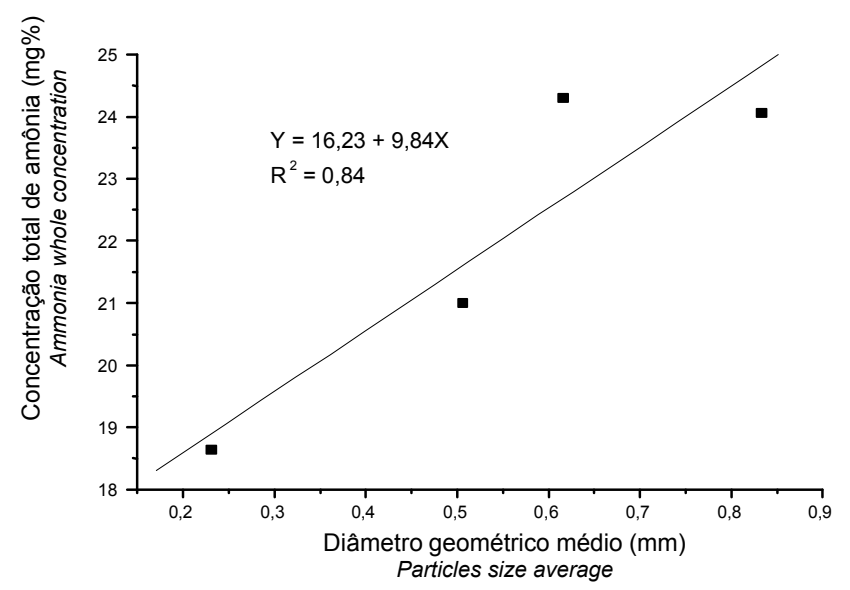

Figura 1 - Concentração total de amônia do conteúdo cecal em função do diâmetro geométrico médio das partículas.

Figure 1 - Ammonia whole concentration in the caecal content, according to the average particle size.

Trabalhando com coelhos Rocha et al. (2000) também não observaram efeito do tamanho de partícula do feno de coastcross sobre o peso do sistema digestivo cheio, conteúdo do sistema digestivo, ceco cheio e conteúdo cecal. Porém, em relação ao peso do sistema digestivo vazio e do ceco vazio os autores citam redução linear $(\mathrm{P}<0,01)$ destas duas variáveis com o aumento da granulometria. A diversidade de resultados em relação as características do sistema digestivo pode ser atribuída a natureza da dieta, conforme demonstram diversos autores (Carabaño, 1989; Gomes, 1996; Santiago et al., 2001).

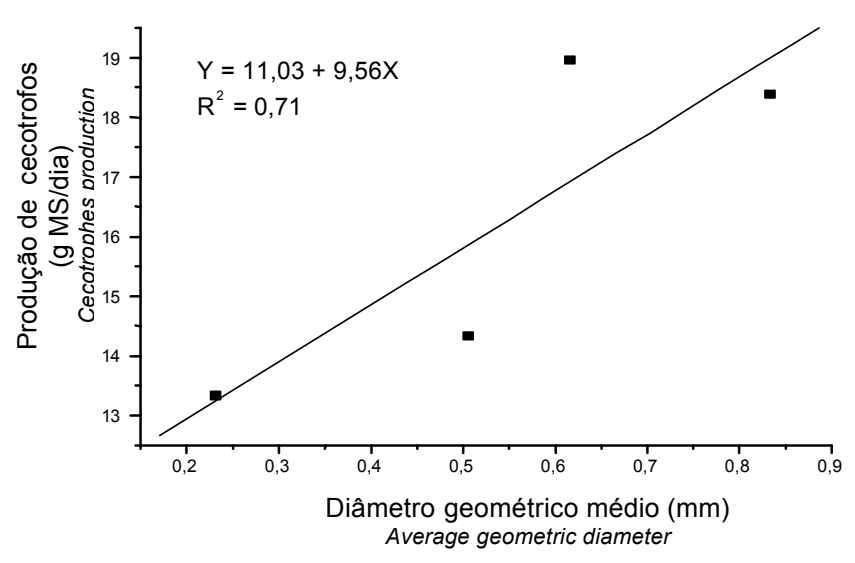

Figura 2 - Produção de cecotrofos, em função do diâmetro geométrico médio das partículas.

Figure 2 - Cecotrophes production, according to the average particle size.

Constam na Tabela 5 os resultados médios encontrados para produção de cecotrofos e contribuição de princípios nutritivos pelos cecotrofos.

Observou-se efeito linear $(\mathrm{P}<0,05)$ do DGM das partículas do bagaço de cana para todas as variáveis analisadas (Figuras 2, 3 e 4). O aumento do tamanho de partícula afetou positivamente a produção de cecotrofos (PC), a contribuição de matéria seca (CMSC) e a contribuição de proteína bruta pelos cecotrofos (CPBC).

Em valores percentuais, foram observados aumentos aproximados de 42,$24 ; 77,31$ e $85,91 \%$ para $\mathrm{PC}, \mathrm{CMSC}$ e CPBC, respectivamente.

Tabela 5 - Produção de cecotrofos (g MS/dia) e contribuição de princípios nutritivos pelos cecotrofos (\%) Table 5 - Cecotrophes production (g DM/day) and contribuition nutrients by cecotrophes

\begin{tabular}{|c|c|c|c|c|c|}
\hline \multirow[b]{2}{*}{$\begin{array}{l}\text { Variável }(\mathrm{g}) \\
\text { Variable }\end{array}$} & \multicolumn{4}{|c|}{$\begin{array}{c}\text { Diâmetro geométrico médio }(\mathrm{mm}) \\
\text { Average geometric diameters }\end{array}$} & \multirow[t]{2}{*}{ CV $(\%)$} \\
\hline & 0,231 & 0,506 & 0,616 & 0,833 & \\
\hline Produção de cecotrofos (PC) & 13,33 & 14,33 & 18,96 & 18,38 & 31,21 \\
\hline Cecotrophes production & & & & & \\
\hline $\begin{array}{l}\text { Contribuição de MS pelos } \\
\text { cecotrofos (CMSC) }\end{array}$ & 10,71 & 14,82 & 17,17 & 18,99 & 19,41 \\
\hline $\begin{array}{l}\text { DM contribution by cecotrophes } \\
\text { Contribuição de PB pelos } \\
\text { cecotrofos (CPBC) }\end{array}$ & 14,34 & 21,78 & 23,16 & 26,66 & 21,86 \\
\hline CP contribution by cecotrophes & & & & & \\
\hline
\end{tabular}

${ }^{1}$ Efeito linear $(\mathrm{P}<0,05)$; ${ }^{*}$ Consumo diário do nutriente dos cecotrofos/consumo diário do nutriente da ração + consumo diário do nutriente dos cecotrofos $x 100$.

${ }^{1}$ Linear effect $(P<.05)$; * Daily intake of nutrients from cecotrophes/ daily intake of nutrients in the diet + daily intake of nutrients from cecotrophes $x 100$. 


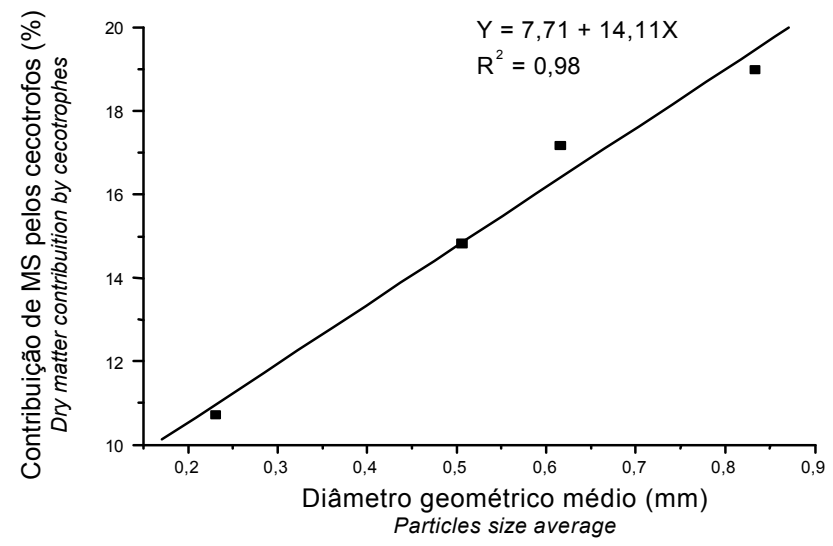

Figura 3 - Contribuição de matéria seca pelos cecotrofos, em função do diâmetro geométrico médio das partículas.

Figure 3 - Dry matter contribuition by caecotrophes, according to the average particle size.

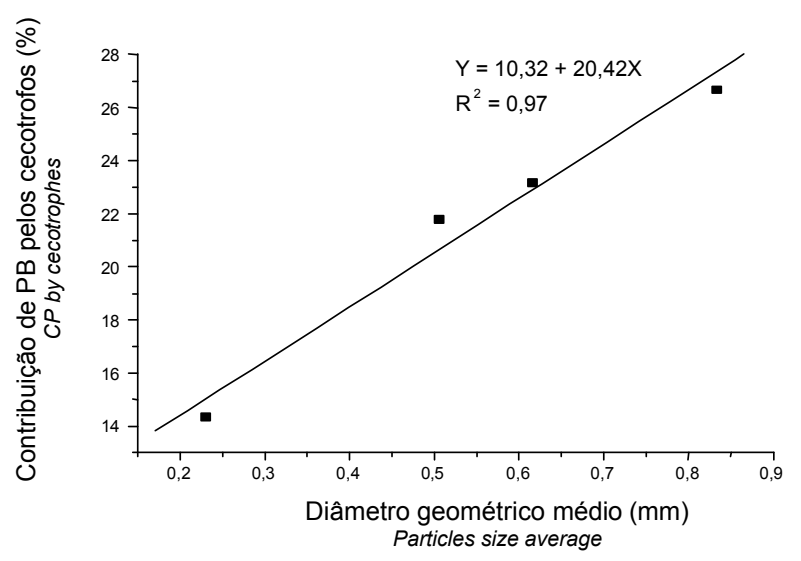

Figura 4 - Contribuição de proteína bruta pelos cecotrofos, em função do diâmetro geométrico médio.

Figure 4 - Crude protein contribuition by cecotrophes, according to the average particle size.

Tabela 6 - Composição Química dos cecotrofos na base seca

Table 6 - Chemical composition of the cecotrophes on dry matter

\begin{tabular}{|c|c|c|c|c|c|}
\hline \multirow[b]{2}{*}{$\begin{array}{l}\text { Variável }(\mathrm{g}) \\
\text { Variable }\end{array}$} & \multicolumn{4}{|c|}{$\begin{array}{l}\text { Diâmetro geométrico médio }(\mathrm{mm}) \\
\text { Average geometric diameter }\end{array}$} & \multirow[t]{2}{*}{ CV (\%) } \\
\hline & 0,231 & 0,506 & 0,616 & 0,833 & \\
\hline $\begin{array}{l}\text { Matéria seca } \\
\text { Dry matter }\end{array}$ & 34,60 & 34,82 & 31,17 & 34,32 & 9,75 \\
\hline $\begin{array}{l}\text { Matéria orgânica } \\
\text { Organic matter }\end{array}$ & 88,12 & 87,99 & 88,25 & 87,76 & 0,95 \\
\hline $\begin{array}{l}\text { Matéria mineral } \\
\text { Ash }\end{array}$ & 11,86 & 12,01 & 11,75 & 12,24 & 6,96 \\
\hline $\begin{array}{l}\text { Proteína bruta } \\
\text { Crude protein }\end{array}$ & 27,16 & 30,51 & 29,25 & 30,28 & 11,11 \\
\hline
\end{tabular}

Os resultados obtidos estão de acordo com os encontrados por Rocha et al. (2000), que, trabalhando com o feno de coastcross como fonte de fibra para coelhos com diferentes granulometrias também, observaram aumento linear $(\mathrm{P}<0,05)$ para $\mathrm{PC}$, CMSC e CPBC.

Esses resultados podem ser explicados pelo fato de as partículas mais finas diminuírem a renovação ("taxa de troca") dos constituintes cecais, pelo maior tempo de retenção no ceco, o que sugere menor produção de cecotrofos e, conseqüentemente, menor contribuição nutricional dos mesmos (Bouyssou et al., 1988).

Os dados da Tabela 6 referem-se à composição química dos cecotrofos na base de matéria seca.

Não foi verificada diferença significativa $(\mathrm{P}>0,05)$ para a composição química dos cecotrofos com o aumento da granulometria do bagaço de cana. Esses resultados estão de acordo com aqueles encontrados por Rocha (1999). 


\section{Conclusões}

O aumento do DGM das partículas não afetou o desempenho, porém influenciou positivamente a concentração de amônia do conteúdo cecal, assim como a produção e a contribuição de matéria seca e proteína bruta pelos cecotrofos.

\section{Literatura Citada}

ALICATTA, M.L.; BONANO, A.; GIACCONE, P.; LETO, G. Effeti del diverso grado di macianatione della farina disidratada di sulla conigli in acrescimento. Rivista di. Coniglicoltura, v.25, p.449-52, 1988.

ASSOCIATION OF OFFICIAL ANALYTICAL CHEMISTS AOAC. Official methods of analysis. 14.ed., Washington, D.C.: 1984. 1141p.

BOUYSSOU, T.; CANDAU, M.; RUEKEBUSCH, Y. Responses matrices du côlon aux constituants parietaux et la finesse de mouture des aliments chez le lapin. Reproduction Nutrition Development, v.28, n.1, p.181-182, 1988.

CARABAÑO, R.M. Influencia de la composición quimica de la dieta sobre distintos parametros cecales de conejos en crecimiento y su relación com el aporte nutritivo de los heces coprofagos. Madrid: Universidade Politécnica de Madrid,1985. 99p. Tese (Doutorado) - Universidade Politécnica de Madrid, 1985.

CARABAÑO, R.M.; FRAGA, M.J.; SANTOMÁ, G.; DE BLAS, J.C. Effect of diet on composition of cecal contents and on excretion and composition of soft and hard feces of rabbits. Journal Animal Science, v.66, n.4, p.901-910, 1988.

CARABAÑO, R.M.; FRAGA, M.J.; DE BLAS, J.C. Effect of protein source in fibrous diets on performance and digestive parameters of fattening rabbits. Journal Applied Rabbit Research, v.12, n.3, p.201-204, 1989.

CHAMPE, K.A.; MAURICE, D.V. Response of early weaned rabbits to source and level of dietary fiber. Journal Animal Science, v.56, n.5, p.1105-1114, 1983.

De BLAS, J.C.; SANTOMA, G.; CARABAÑO, R. Fiber and starch levels in fatterning rabbit diets. Journal of Animal Science, v.63, n.3, p.1897-1904, 1986.

DIAS, J.C.C.A. Níveis decrescentes de proteína em dietas suplementadas com complexo enzimático para coelhos em crescimento. Belo Horizonte: Universidade Federal de Minas Gerais, 1999. 42p. Dissertação (Mestrado em Zootecnia) - Universidade Federal de Minas Gerais, 1999.

FERREIRA, R.G. Utilização do bagaço de cana de açúcar tratado por pressão de vapor ou por hidróxido de sódio na alimentação de coelhos em crescimento. Lavras: Escola Superior de Agricultura de Lavras, 1991. 76p. Dissertação (Mestrado em Zootecnia) - Escola Superior de Agricultura de Lavras, 1991.

FRAGA, M.J. Protein digestion. In: DE BLAS, C., WISEMAN, J. (Eds.). The nutrition of the rabbit. Cambridge: CABI Publishing, 1988. p.39-53.

GIDENNE, T. Evaluation nyethérmérale des produts de la fermentetion bactériene dans le tube digestif du lapin en croissance. Relations avec la teneur en liguines de la ration. Annales Zootechnie, v.53, n.2, p.121- 136, 1986.

GIDENNE, T. Measurement of the rate of passage in restricted fed rabbit: effects of dietary cell wall level on the transit of fibre particles of different sizes. Animal Feed Science and Technolgy, v.42, n.1/2, p.151-163, 1993.

GOMES, A.V.C. Utilização de diferentes fontes de fibra, na alimentação de coelhos em crescimento. Belo Horizonte: Universidade Federal de Minas Gerais, 1996. 129p. Tese (Doutorado em Ciência Animal) - Universidade Federal de Minas Gerais, 1996.

GOMES, A.V.C.; FERREIRA, W.M. Composição química e contribuição nutritiva de cecotrofos de diferentes dietas. Revista Brasileira de Zootecnia, v.28, n.6, p.1297-1301, 1999.

HARRIS, L.E. Os métodos químicos e bioquímicos empregados na análise de alimentos. Gainsville: Universidade da Flórida, 1970. Paginação descontínua.

LAPLACE, J.P.; LEBAS, F. Le transit digestif chez lapin. VII. Influence de la finesse du broyage des constituants dum aliment granulé. Annales Zootechnie, v.26, n.3, p.413-420, 1977.

LAPLACE, J.P. Le transit digestif chez les monogastriques. III. Comportament (pris de nowrriture - caecotrophie), motricité et transit digestifs, et pathogénie des diarrhées chez le lapin. Annales Zootechnie, v.27, n.2, p.225-265, 1978.

LEBAS, F.; COUDERT, P.; ROOUVIER, A.; ROCHAMBEAU, H. EI conejo. Cria y patologia. Roma: Organización de las Naciones Unidas para la Agricultura y la Alimentación, 1986. 278p. (Coleciones FAO,19)

MARTIN, S. Particle size reduction. In: NFIA feed manufacturing short course. Kansas: Kansas State University, 1988. 10p.

PROTO, V. Aspetti aplicative della ciecotrofia nell allevamento del coniglio. Rivista di Coniglicoltura, v.11, p.26-35, 1984.

ROCHA, J.C.C.; GOMES, A.V.C.;CRESPI, M.P.A. et al. Effect of coast cross ( Cynodon dactylon) hay's particle size on caecotrophy and some digestive parameters. In: WORLD RABBIT CONGRESS, 7., 2000, Valencia. Proceedings... Valencia, 2000. p.1-3.

SANTIAGO, G.S.; FERREIRA, W.M.; DIAS, J.C.C.A. et al. Características do sistema digestório e composição química do conteúdo cecal de coelhos em crescimento alimentados com dietas suplementadas com enzima. ARS Veterinaria, v.17, n.1, p.51-57, 2001.

VALENTE, S.S.; SANTIAGO, G.S.; FERREIRA, W.M. et al. Desempenho de coelhos em crescimento recebendo dietas com suplementação enzimática. Arquivo Brasileiro de Medicina Veterinária e Zootecnia, v.52, n.2, p.173-177, 2000.

Van SOEST, P.J. Development of a comprehensive system of feed analysis and its application to forages. Journal of Animal Science, v.26, n.1, p.119-128, 1967.

Van SOEST, P.J.; ROBERTSON, J.B.; LEWIS, B.A. Method for dietary fiber, neutral detergent fiber and starch polysaccharides in relation to animal nutrition. Journal of Dairy Science, v.74, n.10, p.3583-3597, 1991.

ZANOTTO, D.L.; BELLAVER, C. Método de determinação da granulometria de ingredientes para uso em rações de suínos e aves. Concórdia: EMBRAPA-CNPSA, 1996. p.1-2. (Comunicado Técnico)

R. Bras. Zootec., v.32, n.4, p.935-941, 2003

Recebido em: 20/08/02 Aceito em: 22/10/02 